\title{
PERIPHERAL NEUROECTODERMAL TUMOUR (PNET) LUNG DIAGNOSED BY FNAC: A RARE CASE REPORT
}

\author{
Brahmaiah Chari K. R ${ }^{1}$, Vinay H. Shankar², Lakshmi Rao ${ }^{3}$, Brij Mohan Kumar Singh ${ }^{4}$, Deepak Nayak M ${ }^{5}$
}

\section{HOW TO CITE THIS ARTICLE:}

Brahmaiah Chari K. R, Vinay H. Shankar, Lakshmi Rao, Brij Mohan Kumar Singh, Deepak Nayak M. "Peripheral Neuroectodermal Tumor (PNET) Lung Diagnosed by FNAC: A Rare Case Report". Journal of Evolution of Medical and Dental Sciences 2014; Vol. 3, Issue 22, June 02; Page: 5964-5968,

DOI: $10.14260 /$ jemds/2014/2690

\begin{abstract}
We report a rare case of peripheral neuro-ectodermal tumor (PNET) in lung diagnosed by USG- guided FNAC in lung of a 19 year old male, who presented with cough, hemoptysis and pleuritic chest pain. CT chest showed a homogeneous mass in left posterior segment of lung with areas of necrosis. CT abdomen and bone scan studies were normal. Fine needle aspiration (FNA) revealed cellular smears comprised of small round blue cells arranged in rosettes, sheets, blue cells having fine chromatin, scant cytoplasm in an inflammatory background. Biopsy was advised for evaluation of small round blue cell to further typing and confirmation for further management. CTguided trucut biopsy revealed lesion with small round blue cells had round nuclei, fine chromatin with scant cytoplasm arranged in sheets, rosettes in thin fibrous septae. Immunohistochemistry (IHC) showed malignant cells were positive for CD 99, synaptophysin and chromogranin and negativity for CD45 and Cytokeratin.
\end{abstract}

KEYWORDS: PNET-Peripheral neuroectodermal tumor, FNAC- Fine needle aspiration cytology, CTComputerized tomography, USG- Ultra sonogram, IHC-Immunohistochemistry, CD-Cluster differentiation.

INTRODUCTION: PNET is a rare tumor, classically described under small round blue cell tumors with neuro-ectodermal differentiation. ${ }^{1}$ It is an infrequent tumor found in infants and children, especially in thorax, suspected to arise from intercostal nerves. ${ }^{2} \mathrm{Few}$ isolated cases have been observed in visceral sites such as lungs, kidney, oral cavity and uterus; very few cases diagnosed in thoracic cavity by cytology to the best of our knowledge. ${ }^{2}{ }^{3}$ We herein present a case of PNET in lung diagnosed by FNAC which was confirmed on biopsy with the aid of immunohistochemistry(IHC).

CASE DETAILS: 19 year old male presented to the hospital with presenting complaints of cough, chest pain, hemoptysis and weight loss. No lymphadenopathy was detected. Peripheral smear findings were normal, except for a slightly raised total leucocyte count. However, no abnormal cells/ immature cells were found in the smear. Mantoux test was negative. Chest Radiography (CXR) showed a homogeneous soft tissue shadow in the left lower zone with a smooth convex border and widening of intercostal space (Fig-1). Computerized Tomography (CT)-Chest showed homogeneous mass in left lower posterior segments with focal areas of necrosis (Fig -2). CT -Abdomen and Bone scan - Normal study. 


\section{CASE REPORT}

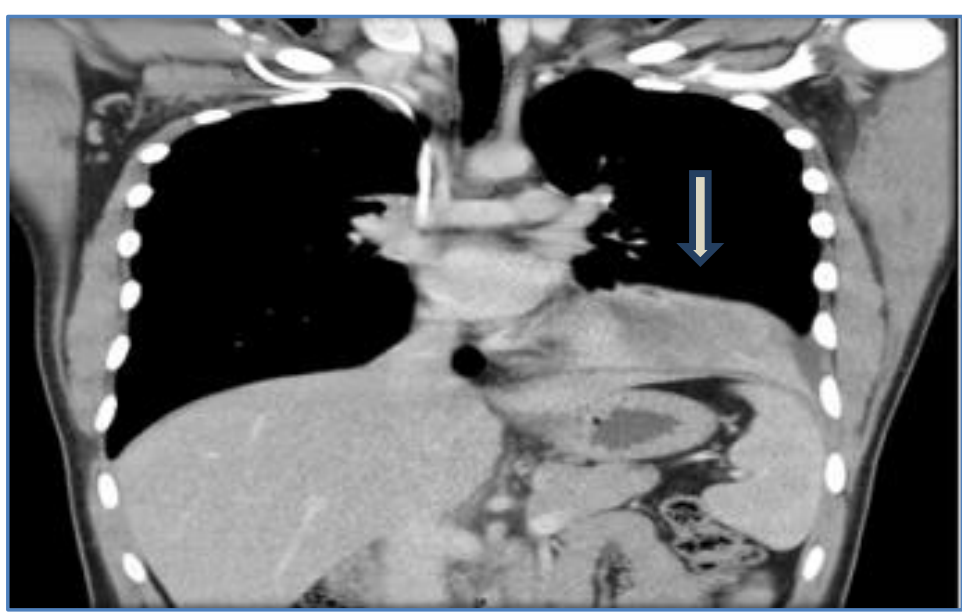

Fig. 1: Chest $\mathrm{x}$-ray P-A view showing homogenous mass in left lower zone

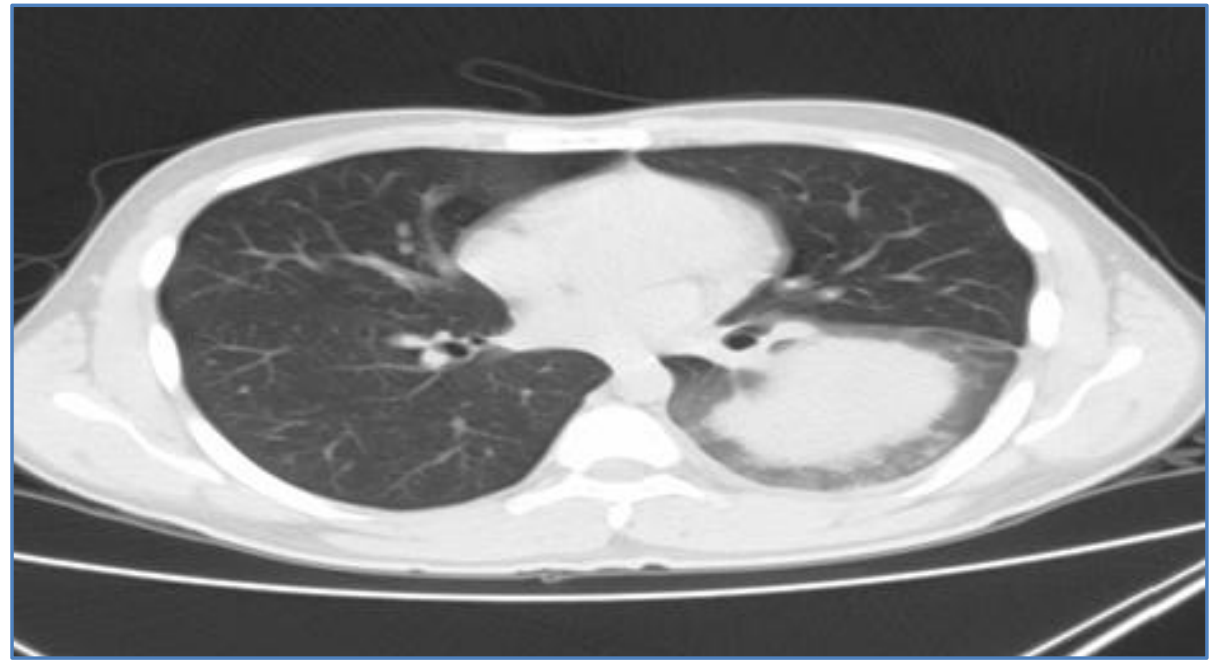

Fig. 2: CT- Chest showed left lung homogeneous mass in postero -lateral segments with focal area of necrosis and minimal effusion

Ultrasound-guided fine needle aspiration cytology (FNAC) of the mass was performed, which showed malignant small round blue cells arranged in nests and dyscohesive sheets having fine chromatin, high N: C ratio, inconspicuous nucleoli and scant cytoplasm (Fig. 3).Based on above findings, a cytologic diagnosis of a small round blue cell tumor was given and we requested a USGguided biopsy for classification and subtyping of tumor.

Based on the above, a CT- guided trucut biopsy was done which was $1 \mathrm{~cm}$ in length and microscopically showed a lesion with small round blue cells. The tumor cells had round nuclei, fine chromatin with scant cytoplasm; arranged in sheets, rosettes in thin fibrous septae (Fig. 4). IHC study revealed that the tumor cells were positive for CD 99 (Fig. 5), synaptophysin and chromogranin and negative for CD45 and Cytokeratin (Fig. 6). 


\section{CASE REPORT}

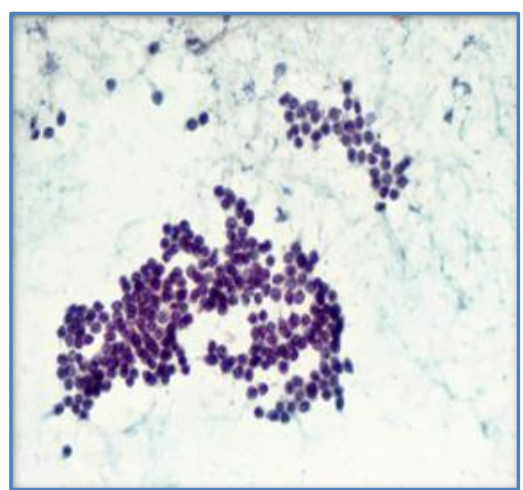

Fig. 3: Cytology smears show malignant small round blue cells arranged in nestsand dyscohesive sheets (Papanicolaou stain $\mathrm{x}$ 100)

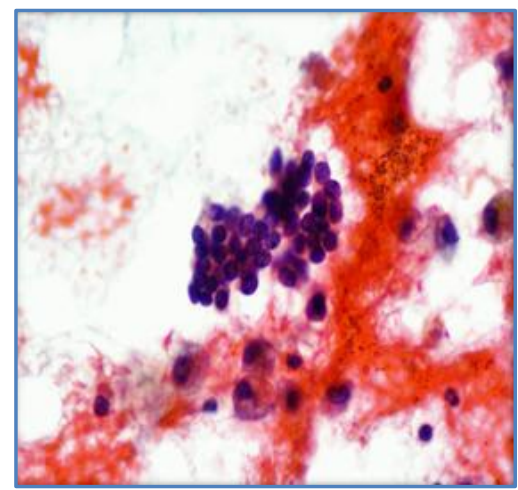

Fig. 4: Cytology smears show malignant small round blue cells arranged in dyscohesive sheets; (Papanicolaou stain $x$ 400)
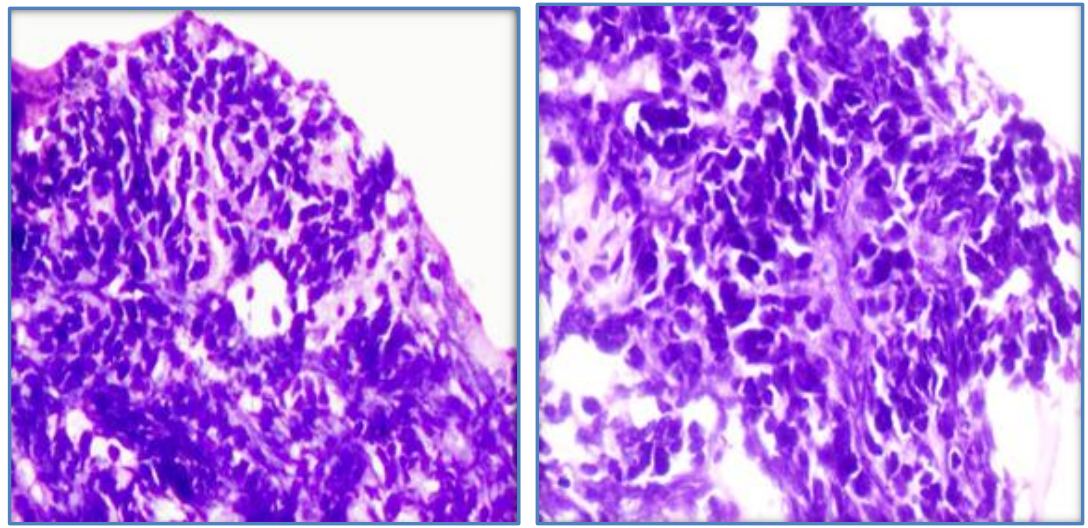

Fig. 5: Small round blue cells arranged in sheets, rosettes, traversed by thin fibrous strands [Haematoxylin\& Eosin ; 200x(left)\& 400x(right)]

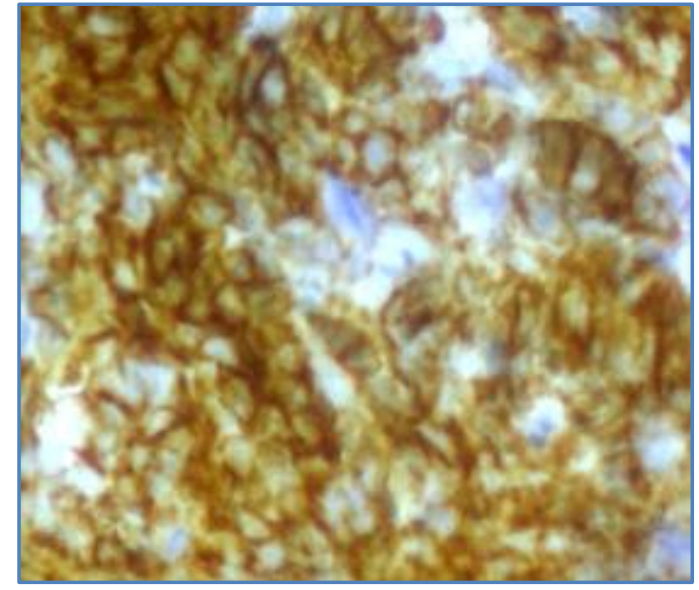

Fig. 6: IHC: CD 99 Positive in tumour cells

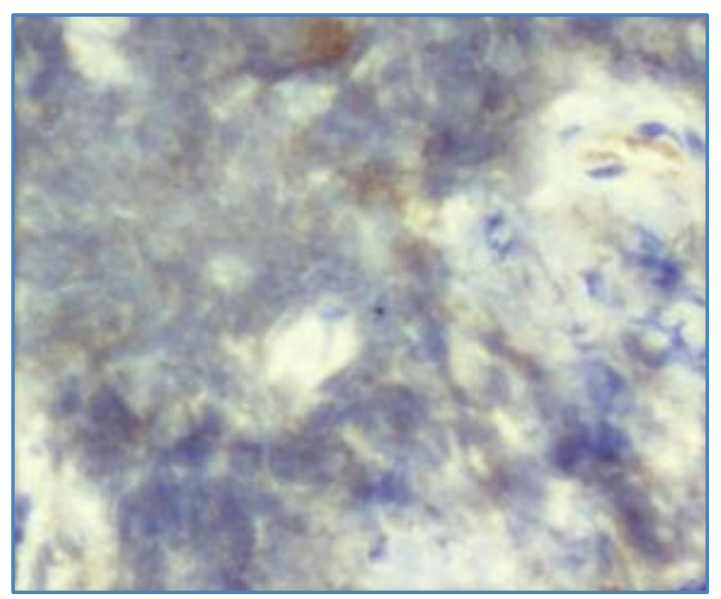

Fig. 7: IHC : CK Negative in tumour cells 
DISCUSSION: Peripheral primitive neuroectodermal tumor (PNET) belong to small round blue cell tumor group, may involve more than one site and can involve the supra-tentorium, spinal canal, palate as the usual sites. The other common locations of PNET originating from the peripheral nerve are the chest wall, head and neck, retroperitoneum, pelvis and extremities. ${ }^{2,3,4}$

Extra-cranial sites like bladder, mediastinum, and lung are rare. Askin tumors are small round cell malignant tumors found in the thoraco-pulmonary region and were first described by Askin in 1979. The family of Ewing sarcoma (ES) tumor includes the classical ES (osseous origin), atypical ES (extra-osseous). PNET arising from lung and Askin tumor; though belonging to same family; are not synonymous. Kuzucu et al., 5, 6 reported a case of multifocal extra-skeletal Ewing sarcoma in mediastinum. In a similar study conducted by Ahmad et al., ${ }^{7}$ amongst a total of 24 cases, only one case of PNET was seen involving the mediastinum.

The common presentation in patients with PNET of the chest wall is chest pain, respiratory distress or a chest wall mass. ${ }^{2,4}$ These tumors do not produce biologically active substances detectable in blood or urine. The presentation with hemorrhagic pleural effusion as in the index case has also been described. ${ }^{8}$

Radiological investigations include CT and MRI.The characteristic CT picture in the patient with Askin tumor/PNET is that of a heterogeneous mass of chest wall origin with areas of necrosis and hemorrhage with an intra-thoracic component. ${ }^{9}$

Cytogenetic studies have demonstrated a similar type of genetic abnormality in PNET tumors and ES tumors, which is translocation of $\mathrm{t}(11 ; 22)$ (q24; q12), giving rise to the EWS/FLI-1 (Ewing sarcoma gene/ Friend Leukemia Virus Integration 1 gene) fusion gene. ${ }^{10}$

The prognosis of the tumor is more related to its anatomical spread to the adjacent structures.

Involvement of bone, pleura and epidural space is considered a bad prognostic factor for survival; especially in younger patients. ${ }^{3}$ The accepted protocol for the management of this tumor is neoadjuvant chemotherapy plus surgical excision of the tumor; followed by post- operative chemotherapy with or without radiotherapy. The neo-adjuvant chemotherapy leads to better local control of the disease. 11,12

CONCLUSION: With this case, we propose that PNET should be always kept in the list of differential diagnosis of thoracic tumors especially in children and adults. A multimodal approach includes cytology and cell block which in conjunction with radiology; could be as good as biopsy, so that early chemotherapy and radiotherapy should be offered to the patient long for term cure.

\section{REFERENCES:}

1. Askin FB, Rosai J et al .Malignant small cell tumor of the thoracopulmonary region in childhood: a distinctive clinicopathologic entity of uncertain histogenesis. Cancer 1979;43:2438-51

2. Shamberger et al. Malignant small round cell tumors (Ewings/ PNET) of chest wall . J Pediatr Surg 1994;29:179-85

3. Berg H, Rijn R, Merks J. Management of tumors of the chest wall in childhood: A review. J Pediatr Hematol Oncol 2008; 30: 214-21.

4. Gaude GS, Malur PR, Kangale R, Anurshetru S. Primitive neuro-ectodermal tumor of the lung in an adult. Lung India. 2009; 26 (3):89-91. 
5. Kuzucu A, Erkal HS, Soysal O, Serin M. Extra-skeletal Ewing sarcoma presenting with multifocal intrathoracic mass lesions associated with mediastinal shift. Ann Thorac Surg 2006; 81: 1487-8.

6. Cabezali R et al. Askin's tumor of the chest wall: a case report in an adult. J Thorac Cardiovasc Surg 1994; 107: 960-2.

7. Ahmad R, Mayol BR, Davis M, Rougraff BT. Extra skeletal Ewing's sarcoma. Cancer 1999;85: 725-31.

8. Pandit S, Mukherjee S, Bhattacharya S, Datta chaudhuri A, Bhuniya S, Deb J, Bhanja P. A rare mediastinal tumour in a young male mimicking massive pleural effusion. Lung India. 2012;29(1):66-9.

9. Winer-Muram HT, Kauffman WM, Gronemeyer SA, Jennings SG. Primitive neuroectodermal tumors of the chest wall (Askin tumors): CT and MR findings. AJR1993;161: 265-8.

10. Yoshino $\mathrm{N}$ et al. Diagnostic significance and clinical applications of chimeric genes in Ewing's sarcoma. Biol Pharm Bull 2003;26:585-89.

11. Parikh M, Samujh R, Kanojia RP, Mishra AK, Sodhi KS. BAL Peripheral primitive neuroectodermal tumor of the chest wall in childhood: clinico-pathological significance, management and literature review. Chang Gung Med J. 2011; 34(2):213-7.

12. Shamberger RC et al. Ewing sarcoma of the rib: Results of the intergroup study with analysis of outcome by timing of resection. J Thorac Cardiovasc Surg2000; 119: 1154-61.

\section{AUTHORS:}

1. Brahmaiah Chari K. R.

2. Vinay H. Shankar

3. Lakshmi Rao

4. Brij Mohan Kumar Singh

5. Deepak Nayak M.

\section{PARTICULARS OF CONTRIBUTORS:}

1. Assistant Professor, Department of Pathology, Melaka Manipal Medical College, Manipal University.

2. Assistant Professor, Department of Pathology, American University of Antigua Medical College, Manipal Education of America (LLC), University Park, Coolidge, St. Johns Antigua, Antigua and Barbuda.

3. Consultant Pathologist, Department of Pathology, Armed Forces Hospital Muscat, Oman.

4. Assistant Professor, Department of Pathology, Melaka Manipal Medical College (Manipal Campus), Manipal University.
5. Assistant Professor, Department of Pathology, Kasturba Medical College - Manipal, Manipal University.

\section{NAME ADDRESS EMAIL ID OF THE CORRESPONDING AUTHOR:}

Dr. Brahmaiah Chari K. R,

Assistant Professor,

Department of Pathology,

Melaka Manipal Medical College,

Manipal University,

Manipal-576104.

Email: dr.brahma@yahoo.co.in

Date of Submission: 14/05/2014.

Date of Peer Review: 15/05/2014.

Date of Acceptance: 24/05/2014.

Date of Publishing: 28/06/2014. 